\title{
Adult Attachment, Emotional Dysregulation and Metacognitive Functions in Patients with Personality Disorders
}

\author{
Sebastiano Maurizio Alaimoㅂ, Maura Ignazia Cascio² \\ ${ }^{1}$ ISPEM, Caltanissetta, Italy \\ ${ }^{2}$ Kore University of Enna, Italy; Cefpas, Centre of Education and Training of Public Health Professionals, \\ Caltanissetta, Italy \\ Email:mauracascio@gmail.com
}

Received 23 October 2015; accepted 23 November 2015; published 26 November 2015

Copyright (C) 2015 by authors and Scientific Research Publishing Inc.

This work is licensed under the Creative Commons Attribution International License (CC BY).

http://creativecommons.org/licenses/by/4.0/

cc) (i)

\section{Abstract}

As Ainsworth $(1982,1989)$ and Bowlby $(1979,1980)$ pointed out, all infants develop some form of attachment to their primary caregiver. Indeed, attachment began at infancy and continued throughout life. Secure attachment is a necessary precursor of the ability to regulate affect and to reflect on the emotional functioning of self and others (Fonagy, 2001). According to Hazan and Shaver (1987), the purpose of this survey is to investigate the relationship between attachment styles and emotional dysregulation, and between adult attachment and metacognition in patients with personality disorders. The research has involved 120 participants, aged 18 - 65 years and recruited during psychotherapy training. Control group is formed by 60 adults (mean $=30.07$; standard deviation = 14.09); experimental group is formed by 60 patients with personality disorder (mean $=31.88$; standard deviation $=12.21)$ grouped into three clusters: $A$ (the "odd, eccentric" cluster), B (the "dramatic, emotional, erratic" cluster), and C (the "anxious, fearful" cluster). Participants completed the following tests: Experiences in Close Relationships Inventory, ECR, Alexithymia Scale, TAS-20 and Metacognitive Functions Screening Scale, MFSS-30. The results confirm the relationship between attachment styles, emotional dysregulation, and metacognitive functions in patients with personality disorders. More specifically, adult attachment and metacognitive functions seem to be positively related, while adult attachment and emotional dysregulation seem to be inversely related.

\section{Keywords}

Adult Attachment, Emotional Dysregulation, Metacognitive Functions, Personality Disorders 


\section{Introduction}

Bowlby's $(1969,1973,1980)$ attachment theory is a useful framework for understanding how early adverse experiences influence later emotional and behavioural development. According to Bowlby, proximity-seeking to the attachment figure in the face of threat is the "set-goal" of the attachment behavioural system. Early experiences with caregivers gradually give rise to a system of thoughts, memories, beliefs, expectations, emotions, and behaviours about the self and others. As children develop in line with environmental and developmental changes, they incorporate the capacity to reflect and communicate about past and future attachment relationships (Ainsworth, 1982, 1989; Bowlby, 1979, 1980). In this system, Internal Models regulate, interpret, and predict attachment-related behaviour in the self and the attachment figure like as a romantic relationship.

According to Bowlby's attachment theory, Hazan and Shaver (1987) classified adults into these attachment styles: secure, dismissing, preoccupied, and fearful. Later, Collins and Read (1990) assumed a precise relationship between adult attachment styles and metacognitive functioning (Flavell, 1976, 1979, 1981, 1987). Consisted of both monitoring and regulation aspects, Flavell defined metacognition as follows: "In any kind of cognitive transaction with the human or non-human environment, a variety of information processing activities may go on. Metacognition refers, among other things, to the active monitoring and consequent regulation and orchestration of these processes in relation to the cognitive objects or data on which they bear, usually in service of some concrete goal or objective" (Flavell, 1976: p. 232). Indeed, metacognitive functioning includes the abilities of representing emotions and mental events, attributing mental states to oneself and to other persons, and predicting behaviors on the basis of mental representations.

The increased interest in metacognition derives from the connection with the Theory of Mind (Baron-Cohen, Leslie, \& Frith, 1985; Premack \& Woodruff, 1978), with the mentalization (Bateman \& Fonagy, 2004), with the alexitimia (Taylor, Bagby, \& Parker, 1997; Caretti et al., 2011) and with the social cognition (Brüne, AbdelHamid, Lehmkämper, \& Sontag, 2007). Semerari et al. (2008), and Dimaggio and Lisaker (2011) provided a more specific definition of metacognition including:

1) the abilities of inferring emotions and mental events from facial expressions, somatic states, behaviours and actions,

2) the abilities of reflecting on mental states,

3) the abilities of using mental states in application of problem-solving strategies or interpersonal conflicts, as human suffering.

According to the Authors mentioned above, meta cognitive functioning provides:

1) perceiving themselves as intentional agents, feeling emotions and developing thoughts differently by others. In other words, another person's may affect our thoughts and feelings, but he doesn't determine them. This process provides the ability to represent their own and others' mental states through facial expression and behavior;

2) understanding mental states, recognizing the link between thoughts, feelings and events. It means that a person can either operate in a subjective or objective frame, distinguishing between perception and memory, dreams and fantasies;

3) promoting synthetic construction of self and others, and use those judgments to solve problems and manage pain (Carcione \& Falcone, 1999; Carcione, Falcone, Magnolfi, \& Manaresi, 1997; DiMaggio \& Lysaker, 2011; Semerari et al., 2003, 2008).

In 1991, Fonagy provided more specific clinical and theoretical considerations concerning the treatment of borderline patients. The failure of adult mental processing in borderline states had been apparent to most clinicians: in order of their dysfunctional attachment style, they have severe difficulty understanding their mental states and assigning mental states to others. Different studies conducted by the 3rd Center of Cognitive Psychotherapy of Rome sustained that patients with personality disorders had metacognitive deficits and that there are differences in metacognitive processing across these patients (for example, some patients with personality disorders find difficult to describe their emotions, while others are less able to distinguish fantasy from reality). Indeed, a lot of studies have provided evidence for a link among metacognition and psycopathology (Dimaggio \& Lysaker 2011; Alaimo, 2012), paying attention to metacognition as an important factor in mental health, because it allows perceiving themselves as intentional agents and monitoring feelings (Carcione, Falcone, Magnolfi, \& Manaresi, 1997). To determine the relationship among attachment style and metacognition, Kobak and Hazan (1991) assumpted that Internal Working Models (IWM) represented a flexible basis for developing adult attachment style. The internal working model is a cognitive framework comprising mental representations for understanding 
the world, self and others. So, adult attachment style plays a role in the process of partner selection, allowing the ability to build trusting relationships. Secure attachment is a healthy attachment style that enables individuals to work autonomously as well as with others when appropriate. Secure attachments are characterized by internal regulatory mechanisms that allow individuals to be flexible and constructive in their interpersonal relationships, learning about when and where it is appropriate to use metaconitve functioning.

In order to these features, the purpose of this survey is to investigate the relationship between attachment styles, emotional dysregulation, and metacognition in patients with personality disorders. More specifically, this survey analyses the relationship between metacognition and adult attachment styles in two separate groups of subjects (the experimental group and the control group). Psychological testing has been used as a baseline measure of the patient's emotional status.

\section{Methodology}

\subsection{Instruments}

Alexitimia was investigated through the Toronto Alexithymia Scale-TAS-20 (Bagby, Parker, \& Taylor, 1994), a self-report questionnaire composed of 20 items rated on a 5-point Likert (whereby $1=$ strongly disagree and 5 = strongly agree). The TAS-20 has 3 subscales congruent with the alexithymia construct: Difficulty Identifying Feelings (DDI), Difficulty Describing Feeling (DDE), and Externally-Oriented Thinking (POE). The total alexithymia score is the sum of responses to all 20 items, while the score for each subscale factor is the sum of the responses to that subscale. The TAS-20 uses cutoff scoring: equal to or less than $51=$ non-alexithymia, equal to or greater than $61=$ alexithymia. Scores between 52 to $60=$ possible alexithymia. TAS has a good internal consistency (Cronbach's $\alpha=.81$ ) and adequate levels of convergent and concurrent validity.

Metacognitive functions were investigated through the Metacognitive Functions Screening Scale-MFSS-30 (Alaimo \& Schimmenti, 2013), a self-report questionnaire composed of 30 items rated on a 4-point Likert (whereby $0=$ strongly disagree and $3=$ strongly agree). The total MFSS-30 score is the sum of responses (mean = 57.99; st. dev. = 12.18). Furthermore, the MFSS-30 provides 4 sub-scales: CRE, as the ability to understand others' Emotional States (mean = 9.77; st. dev. $=3.96$ ), measures the ability of describing and identifying personal and social emotions (Cronbach's alpha $=.79$ ); CRC, as the ability to understand Causal Relationships (mean $=15.87$; st. dev. $=4.22$ ), measures the ability to identify causality, as the relationship between a cause and its effect (Cronbach's alpha $=.71$ ); CDD, as the ability to Judge The Distance of objects from one another and from ourselves (mean $=24.28$; st. dev. $=5.33$ ), measures the ability to infer the mental state of another person in terms of beliefs, desires, intentions, expectations (Cronbach's alpha $=.78$ ); CDP, as the ability to Ponder Situations And Problems (mean = 8.07; st. dev.=2.15), measures critical thinking and the ability to evaluate situations and problems to better apply the previous experiences with actual events (Cronbach's alpha $=.70$ ). MFSS-30 has a good internal consistency (Cronbach's alpha $=.88$ ) and adequate levels of convergent and concurrent validity. Furthermore, Cronbach's $\alpha$ for the subscale' coefficients is ranged from 0.70 to 0.79 (Alaimo \& Schimmenti, 2013). For further information visit the web site http://www.stateofmind.it/2014/02/metacognitive-functions-screening-scale/.

Adult attachment was measured through the Experiences in Close Relationships Inventory, ECR (Brennan, Clark, \& Shaver, 1998). The ECR is a self-report questionnaire composed of 36 items rated on a 7-point Likert (whereby 1 = strongly disagree and 7 = strongly agree). Factor analysis identified two relatively orthogonal continuous attachment dimensions, as shown in Figure 1 and labeled "Anxiety" (ANS) and "Avoidance" (EVI), each containing 18 items. Higher scores on the Anxiety and Avoidant subscales indicate higher levels of attachment anxiety and attachment avoidance, respectively.

The secure style of attachment is characterized by low anxiety and low avoidance; the preoccupied style of attachment is characterized by high anxiety and low avoidance; the dismissive avoidant style of attachment is characterized by low anxiety and high avoidance; and the fearful avoidant style of attachment is characterized by high anxiety and high avoidance (Table 1 ).

Previous studies (Fraley, Waller, \& Brennan, 2000) demonstrated that ECR has high reliability: indeed, Cronbach' $\alpha$ rating of .93 for the Anxiety scale and the .95 for the Avoidance scale. For this survey, researchers have adopted the version of Picardi, Vermigli, Toni, D'Amico, Bitetti, and Pasquini (2002) that has a good internal consistency (Cronbach's $\alpha=.89$ for each scales). 


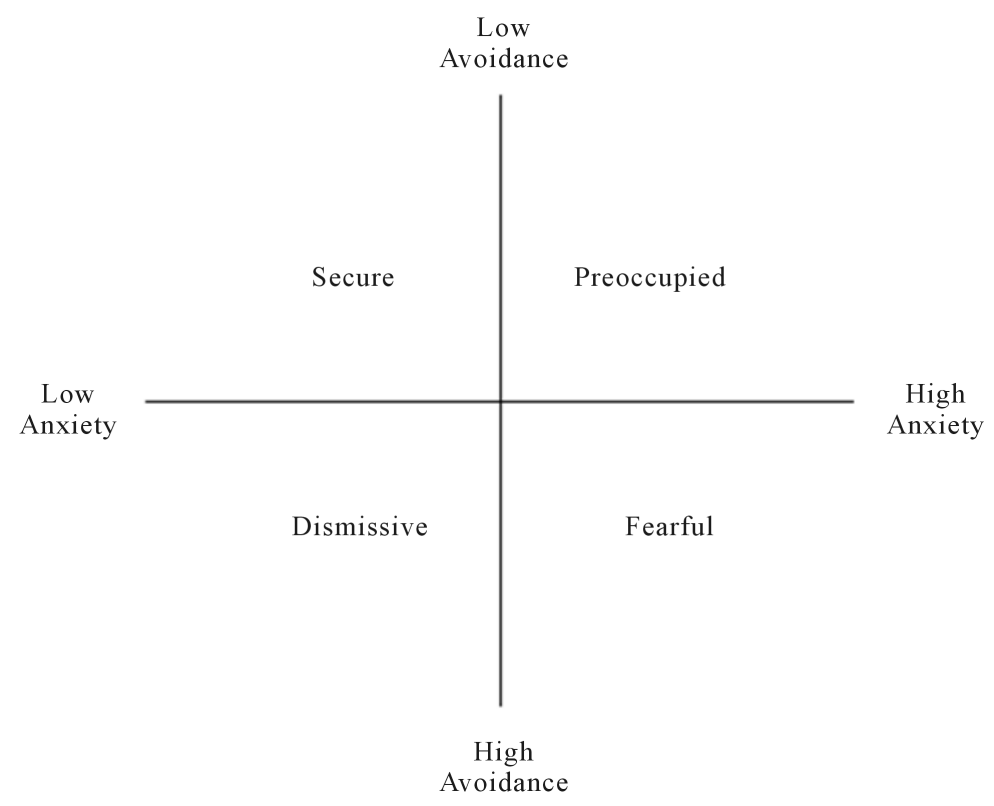

Figure 1. Combinations of anxiety and avoidance: the four attachment styles.

Table 1. Styles of adult attachment (Bartholomew, 1990).

\begin{tabular}{ccc}
\hline & Avoidance & Anxiety \\
\hline Secure attachment & Low level & Low level \\
Dismissing Avoidant attachment & High level & Low level \\
Preoccupied attachment & Low level & High level \\
Fearful Avoidant attachment & High level & High level \\
\hline
\end{tabular}

\subsection{Participants}

This survey provided 120 participants, aged 18 - 65 years (mean $=30.97$; st. dev. $=13.16$ ) and recruited during psychotherapy training in ISPEM (Caltanissetta). Control group (male $=35$; female $=25$ ) is formed by 60 adults (mean $=30.07$; st. dev. $=14.09)$. Instead, experimental group (male $=35$; female $=25$ ) is formed by 60 patients with personality disorders (mean $=31.88$; st. dev. $=12.21$ ) grouped into the three clusters operationally defined in DSM-5: cluster A (the "odd, eccentric" cluster), 26.67\%; cluster B (the "dramatic, emotional, erratic" cluster), 26.67\%; cluster C (the "anxious, fearful” cluster), 46.67\%.

\subsection{Procedure}

The participants have been informed about the purpose of the study and they gave their informed consent. The experimental procedure is been explained, and they participated to the study filling out the questionnaires in a group setting, anonymously, voluntarily, without time restrictions.

In order to test for differences between means from the two separate groups of subjects (the experimental group and the control group), psychological testing has been used as a baseline measure of the patient's emotional status. They have been tested individually in ISPEM in a quiet room that is been arranged for the experimental procedure.

A two-step analysis has been conducted before studying the possible effects of Adult attachment on Metacognitive functions and on emotional dysregulation. An explorative analysis, based on parametric tests, allowed knowing if the subjects' responses varied according to gender and group. At this stage, T-test has carried out. Then, in order to investigate the structure of the relationship among the instrumental variables, Pearson's correlations has applied and the outcomes of both group are assessed. 


\section{Results}

Figure 2 shows a graphical representation of distribution for the investigated variables. As we expected, the experimental group has higher scores on the Anxiety and Avoidant subscales (ECR) that indicate higher levels of attachment anxiety and attachment avoidance, respectively, and alexitimia. Otherwise, the control group has higher scores on Metacognitive Functions Screening Scale (Figure 2).

Table 2 shows a graphical representation of distribution for the styles of adult attachment (Bartholomew, 1990). As we expected, attachment is a specific response requiring a specific features: the control group reaches lower rates of disorganized attachment and higher rates of secure attachment (Table 2)

The results show that the large majority of adults in control group are capable of "secure attachment". Therefore, as we expected, experimental group is more Fearful Avoidant attached than control group. Moreover, related to Dismissing Avoidant and Preoccupied attachment style, results partially confirmed our initial expectations.

In order to know if the subjects' responses varied according to gender and group, T- test has carried out.

Table 3 shows that there are no significant gender differences, except that in Externally-Oriented thinking (POE). Results seem to indicate that males are more emotionally intense than females and they focus on external rather than internal experience. The high value placed on control is confirmed by Moriguchi, Touroutoglou, Dickerson, and Barrett (2013) that demonstrated that women's feelings are relatively more self-focused, whereas men's feelings are relatively more world-focused.

Indeed, as we expected, there are significant group differences: as shown in Table 4, experimental group has problems in emotional regulation and attachment more than the other group.

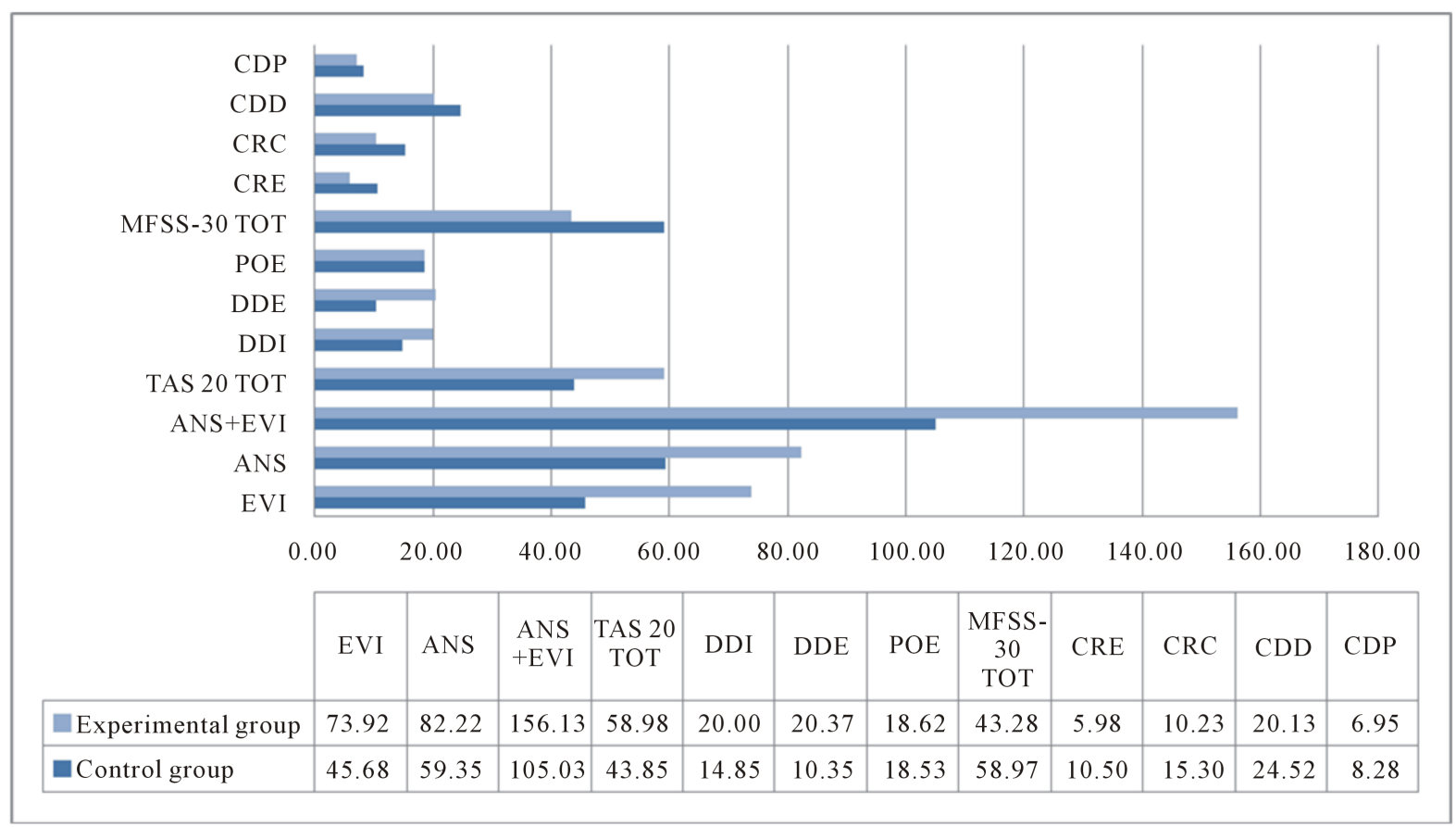

Figure 2. Graphical representation of distributions for the investigated variables.

Table 2. Styles of adult attachment.

\begin{tabular}{ccccc}
\hline & Control group N =60 & $\%$ & Experimental group N $=60$ & $\%$ \\
\hline Secure attachment & 24 & $100 \%$ & 0 & $0 \%$ \\
Dismissing Avoidant attachment & 17 & $55 \%$ & 14 & $45 \%$ \\
Preoccupied attachment & 10 & $55 \%$ & 8 & $45 \%$ \\
Fearful Avoidant attachment & 9 & $19 \%$ & 38 & $81 \%$
\end{tabular}


Table 3. Gender differences, Student's t test.

\begin{tabular}{|c|c|c|c|c|c|}
\hline & \multicolumn{2}{|c|}{ Males $\mathrm{N}=70$} & \multicolumn{2}{|c|}{ Females $\mathrm{N}=50$} & \multirow{2}{*}{$p$-value } \\
\hline & M & SD & M & SD & \\
\hline TAS-20 (total score) & 53.24 & 11.29 & 48.86 & 13.92 & .053 \\
\hline DDI & 16.63 & 5.63 & 15.40 & 6.98 & .386 \\
\hline $\mathrm{DDE}$ & 15.40 & 6.97 & 15.30 & 8.38 & .243 \\
\hline POE & 20.04 & 5.50 & 16.52 & 3.78 & .001 \\
\hline Total MFSS-30 (total score) & 50.53 & 11.36 & 51.96 & 13.34 & .059 \\
\hline CRE & 8.40 & 3.84 & 8.02 & 4.50 & .226 \\
\hline CRC & 12.89 & 4.58 & 12.60 & 4.19 & .354 \\
\hline CDD & 21.70 & 4.39 & 23.20 & 5.67 & .293 \\
\hline CDP & 7.60 & 2.17 & 7.64 & 2.29 & .738 \\
\hline Anxiety + Avoidance (ECR) & 133.26 & 37.72 & 126.84 & 37.38 & .921 \\
\hline Anxiety & 69.96 & 24.52 & 71.94 & 22.53 & .611 \\
\hline Avoidance & 63.30 & 22.50 & 54.90 & 23.06 & .716 \\
\hline
\end{tabular}

Table 4. Group differences, Student’s t test.

\begin{tabular}{|c|c|c|c|c|c|}
\hline & \multicolumn{2}{|c|}{ Control group $\mathrm{N}=60$} & \multicolumn{2}{|c|}{ Experimental group $\mathrm{N}=60$} & \multirow{2}{*}{$p$-value } \\
\hline & M & SD & M & SD & \\
\hline TAS-20 (total score) & 43.85 & 10.00 & 58.98 & 10.16 & .962 \\
\hline DDI & 14.85 & 4.88 & 20.00 & 5.43 & .764 \\
\hline DDE & 10.35 & 3.41 & 20.37 & 7.25 & .000 \\
\hline POE & 18.53 & 4.49 & 18.62 & 5.76 & .042 \\
\hline Total MFSS-30 (total score) & 58.97 & 9.17 & 43.28 & 9.56 & .773 \\
\hline CRE & 10.50 & 3.55 & 5.98 & 3.35 & .462 \\
\hline CRC & 15.30 & 3.16 & 10.23 & 4.00 & .038 \\
\hline CDD & 24.52 & 4.70 & 20.13 & 4.29 & .431 \\
\hline CDP & 8.28 & 2.16 & 6.95 & 2.08 & .540 \\
\hline Anxiety + Avoidance (ECR) & 105.03 & 23.43 & 156.13 & 31.12 & .005 \\
\hline Anxiety & 59.35 & 14.48 & 82.22 & 24.93 & .000 \\
\hline Avoidance & 45.68 & 15.88 & 73.92 & 20.29 & .037 \\
\hline
\end{tabular}

These data seem to confirm the relationship between insecurely attached people and metacognition, and between insecurely attached people and personality disorders.

Emotional self-regulation is the ability to respond to the ongoing demands of experience with the range of emotions in a manner that is socially tolerable and sufficiently flexible to permit spontaneous reactions as well as the ability to delay spontaneous reactions as needed. According to the literature in this field (Basile, Quadrana, \& Monniello, 2009; Dimaggio \& Lysaker, 2011), patients with personality disorders experience more emotional dysregulation than the control group. In particular, they show difficulties in describing feeling (DDE), in focusing experience external rather than internal (POE) and in identifying the causal effect (CRC). The correlation coefficients shown in Table 5 and Table 6 indicate statistically significant bivariate correlations between the variables in both group. More specifically, adult attachment and emotional dysregulation seems to be posi- tively related, while adult attachment and metacognitive functions seems to be inversely related. 
Table 5. Pearson's correlations (Control group).

\begin{tabular}{|c|c|c|c|c|c|c|c|c|c|c|c|c|}
\hline & & $\begin{array}{l}\text { Experiences } \\
\text { lose Relations }\end{array}$ & & & Metac & ognitive fu & nctions & & & $T A S-2$ & total sco & \\
\hline & Anxiety & Avoidance & $\begin{array}{c}\text { Anxiety + } \\
\text { Avoidance }\end{array}$ & CRE & CRC & CDD & CDP & $\begin{array}{l}\text { MFSS } \\
30 \text { Tot }\end{array}$ & DDI & DDE & POE & Alexitimia \\
\hline Anxiety & - & .117 & $.740^{* *}$ & $-.403^{* *}$ & -.212 & -.056 & -.125 & $-.350^{* *}$ & $.406^{* *}$ & $.264^{*}$ & .220 & $.370^{* *}$ \\
\hline Avoidance & .117 & - & $.755^{* *}$ & $-.307^{*}$ & -.132 & $-.605^{* *}$ & -.244 & $-.533^{* *}$ & $.386^{* *}$ & $.301^{*}$ & $.323^{*}$ & $.462^{* *}$ \\
\hline $\begin{array}{l}\text { Anxiety + } \\
\text { Avoidance }\end{array}$ & $.740^{* *}$ & $.755^{* *}$ & - & $-.474^{* *}$ & -.229 & $-.447^{* *}$ & -.248 & $-.593^{* *}$ & $.530^{* *}$ & $.379^{* *}$ & $.364^{* *}$ & $.557^{* * *}$ \\
\hline CRE & $-.403^{* * *}$ & $-.307^{*}$ & $-.474^{* * *}$ & - & .196 & $.353^{* *}$ & .187 & $.650^{* *}$ & $-.697^{* *}$ & -.167 & -.167 & $-.646^{* *}$ \\
\hline CRC & -.212 & -.132 & -.229 & .196 & - & .187 & $.308^{*}$ & $.563^{* * *}$ & -.220 & $-.256^{*}$ & $-.256^{*}$ & -.254 \\
\hline CDD & -.056 & $-.605^{* *}$ & $-.447^{* *}$ & $.353^{* * *}$ & .187 & - & $.331^{* * *}$ & $.783^{* *}$ & $-.375^{* *}$ & $-.486^{* *}$ & $-.486^{* *}$ & $-.545^{* *}$ \\
\hline CDP & -.125 & -.244 & -.248 & .187 & $.308^{*}$ & $.331^{* *}$ & - & $.524^{* *}$ & -.122 & $-.380^{* *}$ & $-.380^{* *}$ & $-.293^{*}$ \\
\hline $\begin{array}{c}\text { MFSS } 30 \\
\text { Tot }\end{array}$ & $-.350^{* *}$ & $-.533^{* *}$ & $-.593^{* *}$ & $.650^{* *}$ & $563^{* *}$ & $783^{* *}$ & $.524^{* *}$ & - & $-.580^{* *}$ & $-.545^{* *}$ & $-.545^{* *}$ & $-.716^{* *}$ \\
\hline DDI & $.406^{* *}$ & $.386^{* *}$ & $.530^{* *}$ & $-.697^{* *}$ & -.220 & $-.375^{* *}$ & -.122 & $-.580^{* *}$ & - & $.639^{* *}$ & .244 & $.847^{* *}$ \\
\hline DDE & $.264^{*}$ & $.301^{*}$ & $.379^{* *}$ & $-.631^{* *}$ & -.175 & $-.379^{* *}$ & -.175 & $-.537^{* *}$ & $.639^{* *}$ & - & .239 & $.755^{* *}$ \\
\hline POE & .220 & $.323^{*}$ & $.364^{* *}$ & -.167 & $-.256^{*}$ & $-.486^{* *}$ & $-.380^{* *}$ & $-.545^{* *}$ & .244 & .239 & - & $.658^{* *}$ \\
\hline Alexitimia & $.462^{* *}$ & $.370^{* *}$ & $.557^{* *}$ & $-.646^{* *}$ & -.254 & $-.545^{* *}$ & $-.293^{*}$ & $-.716^{* *}$ & $.847^{* *}$ & $755^{* *}$ & $.658^{* *}$ & - \\
\hline
\end{tabular}

Note: ${ }^{*} p<.05 ;{ }^{* *} p<.01$.

Table 6. Pearson's correlations (Experimental group).

\begin{tabular}{|c|c|c|c|c|c|c|c|c|c|c|c|c|}
\hline & \multicolumn{3}{|c|}{$\begin{array}{l}\text { Experiences in } \\
\text { Close Relationships }\end{array}$} & \multicolumn{5}{|c|}{ Metacognitive functions } & \multicolumn{4}{|c|}{ TAS -20 total score } \\
\hline & Anxiety & Avoidance & $\begin{array}{l}\text { Anxiety + } \\
\text { Avoidance }\end{array}$ & CRE & CRC & CDD & CDP & $\begin{array}{l}\text { MFSS } \\
30 \text { Tot }\end{array}$ & DDI & DDE & POE & Alexitimia \\
\hline Anxiety & - & -.064 & $.759^{* *}$ & -.006 & -.163 & .018 & -.096 & -.092 & -.062 & .156 & .068 & -.109 \\
\hline Avoidance & -.064 & - & $.601^{* *}$ & -.242 & $-.365^{* *}$ & $-.292^{*}$ & -.177 & $-.400^{* *}$ & .099 & -.161 & $.338^{* *}$ & $.357^{* *}$ \\
\hline $\begin{array}{l}\text { Anxiety + } \\
\text { Avoidance }\end{array}$ & $.759^{* *}$ & $.601^{* *}$ & - & -.163 & $-.368^{* *}$ & -.176 & -.192 & $-.334^{* *}$ & .015 & -.027 & $.275^{*}$ & .145 \\
\hline CRE & -.006 & -.242 & -.163 & - & .220 & $.376^{* *}$ & .195 & $.653^{* *}$ & $-.277^{*}$ & $-.663^{* *}$ & -.188 & $-.728^{* *}$ \\
\hline CRC & -.163 & $-.365^{* *}$ & $-.368^{* *}$ & .220 & - & $.430^{* *}$ & .111 & $.715^{* *}$ & $-.280^{*}$ & -.207 & -.083 & $-.344^{* *}$ \\
\hline CDD & .018 & $-.292^{*}$ & -.176 & $.376^{* *}$ & $.430^{* *}$ & - & $.358^{* *}$ & $.826^{* *}$ & -.085 & $372^{* *}$ & -.193 & $-.420^{* *}$ \\
\hline CDP & -.096 & -.177 & -.192 & .195 & .111 & $.358^{* *}$ & - & $.472^{* *}$ & -.162 & -.075 & -.184 & -.245 \\
\hline $\begin{array}{l}\text { MFSS } 30 \\
\text { Tot }\end{array}$ & -.092 & $-.400^{* *}$ & $-.334^{* *}$ & $.653^{* *}$ & $.715^{* *}$ & $.826^{* *}$ & $.472^{* *}$ & - & -.291 & $-.503^{* *}$ & -.220 & $-.639^{* *}$ \\
\hline DDI & -.062 & .099 & .015 & $-.277^{*}$ & $-.280^{*}$ & -.085 & -.162 & $-.291^{*}$ & - & .121 & $-.310^{*}$ & $.445^{* *}$ \\
\hline DDE & .156 & -.161 & -.027 & $-.663^{* *}$ & -.207 & $-.372^{* *}$ & -.075 & $-.503^{* *}$ & .121 & - & -.026 & $764^{* *}$ \\
\hline POE & .068 & $.338^{* *}$ & $.275^{*}$ & -.188 & -.083 & -.193 & -.184 & -.220 & $-.310^{*}$ & -.026 & - & $.383^{* *}$ \\
\hline Alexitimia & -.109 & $357^{* *}$ & .145 & $-.728^{* *}$ & $-.344^{* *}$ & $-.420^{* *}$ & -.245 & $-.639^{* *}$ & $.445^{* *}$ & $.764^{* *}$ & $.383^{* *}$ & - \\
\hline
\end{tabular}

Note: ${ }^{*} p<.05 ;{ }^{* *} p<.01$. 


\section{Discussion}

The purpose of this survey is to investigate, on the one hand, the relationship between attachment styles and emotional dysregulation, and, from the other hand, metacognition in patients with personality disorders.

As we expected, patients with personality disorders (experimental group) experience anxiety and avoidance more than control group (Basile, Quadrana, \& Monniello, 2009; Dimaggio \& Lysaker, 2011). At the same time, according to the literature in this field (Alaimo, 2012; Basile, Quadrana, \& Monniello, 2009; Dimaggio \& Lysaker, 2011), experimental group scores higher levels in emotional dysregulation (see DDE and POE scales' scores) and lower levels in metacognition (see CRC scales' scores).

In order to investigate the structure of the relationship among the instrumental variables, Pearson's correlations has applied. Results partially confirmed our initial expectations. Although is attachment a direct cause of emotional dysregulation (adult attachment and emotional dysregulation are positively related) and metacognition (adult attachment and Metacognitive functions are inversely related), scores within the groups are very different. In particular:

1) there is a statistically significant correlation (positive) between Alexitimia and adult attachment (ECR) in control group (Anxiety, $.462^{* *}$; Avoidance, $.370^{* *}$ ). This results is partially confirmed in experimental group, where only Avoidance is statistically significant (Avoidance, $.357^{* *}$ );

2) there is a statistically significant correlation (negative) between Metacognitive functioning (MFSS-30) and adult attachment (ECR) in control group. This results is partially confirmed in experimental group where Anxiety $(-.092)$ is not statistically significant.

Both groups show a statistically significant bivariate correlations between MFSS-30' scores, overall in CRE and CDD' scales, attachment and emotional dysregulation. As we expected, the ability to infer the mental state of another person (CDD) provides the ability of describing and identifying personal and social capability (CRE). In order to this, the inversely related relationship among Metacognition and emotional dysregulation confirms that mentalizing is the basis of self-awareness and a sense of identity. Moreover, this ability allows people to shift perspectives. Moreover, both groups show a statistically significant bivariate correlations between the ability to infer the mental state of another person (CDD) and Avoidance (ECR). According to the literature in this field (Ainsworth, 1982, 1989; Bowlby, 1979, 1980), secure attachment is where the child uses the primary caregiver as a secure base from which to explore and, when necessary, has a haven of safety and a source of comfort. If children receive "inadequate care", they use avoidance as an instrument to protect themselves from pain and suffering. When they grow up, they repeat this model in love. The increase of CDD' scores gives an evidence of the difficulty of experimental group in understanding the other people's mental states and taking a different perspective. In this context, the low correlation among CDD and Anxiety (ECR) is explained by the missing link between anxiety and Empathetic Ability.

As Table 2 shows, the large majority of adults in control group are capable of "secure attachment". Therefore, as we expected, experimental group is more Fearful Avoidant attached than the other group. Fearful Avoidant (sometimes called anxious-avoidant) share an underlying distrust of caregiving others with the dismissiveavoidant, but have not developed the amor of high self-esteem to allow them to do without attachment; they realize they need and want intimacy, but when they are in a relationship that starts to get close, their fear and mistrust surfaces and they distance.

\section{Conclusions}

In 1991, Main showed that the absence of metacognitive capacity, the inability to "understand the merely representational nature of their own (and others') thinking" (Main, 1991: p. 128), makes infants and toddlers vulnerable to the inconsistency of the caregiver's behaviour. They are unable to step beyond the immediate reality of experience and grasp the distinction among immediate experience and the mental state which might underpin it. Previous studies demostrated a direct link between the parent's early attachment experiences and personality disorders (Fonagy \& Target, 2006). If children grew up with an insicure attachment pattern, it causes and maintains the symptom, encountering resistance to change. Similarly, this study demostrated the relationship between attachment styles and emotional dysregulation, and, more specifically, between attachment styles and metacognition in patients with personality disorders.

Although the administered instruments are self-reports unable to exactly investigate functioning and features, the most interesting aspects of this survey show: 
- a marked differences between experimental and control group in investigated features. More specifically, patients with personality disorders (experimental group, insecure attachment) score higher levels in emotional dysregulation (alexitimia) and lower levels in Metacognitive functioning;

- a negative correlation between alexitimia (emotional dysregulation as facial imitation, mentalization, empathy, and internal working models-of-self and others) and metacognitive functioning in both groups. Furthermore, correlation is statistically significant $\left(.716^{* *}\right.$ in control group; $.639^{* *}$ in experimental group). In other terms, regardless of diagnostic label, there is a relationship between emotional regulation (alexitimia) and metacognition.

Indeed, the statistically significant correlation (negative) between the ability to shift perspectives (CDD) and emotional dysregulation (alexitimia), and between this feature (CDD) and Avoidance (that measures the difficulty in Adult attachment), confirm that having a different point of view (CDD) is the basic requirement for human relationships. From one hand, in both groups there is a statistically significant correlation (positive) between emotional dysregulation (alexitimia) and avoidance (EVI). This feature is mostly present in adults with an insecure attachment pattern. Therefore, there is a statistically significant correlation (negative) between emotional dysregulation (alexitimia) and metacognition (the best score shows the highest level of functioning). On the other hand, the relatively large numbers of people with fearful avoidant attachment or the missed homogeneity of personality disorders (Cluster A $=27 \%$; Cluster $B=27 \%$; Cluster $C=46 \%$ ) could cause the statistically significant correlation (positive) between anxiety (ANS), Alexitimia and Metacognition only in the experimental group. Moreover, the experimental group has higher scores on the Anxiety and Avoidant subscales (ECR) that indicate higher levels of attachment anxiety and attachment avoidance, respectively.

So, while metacognition is often studied as a one-dimensional phenomenon, this feature may involve capacities that are conceptually distinct. In fact, patients with personality disorders have different scores on one or more of the abilities measured by MFSS-30 (CRE; CRC; CDD; CDP). Consequently, these psychological assessments could be used as a basis for identifying problems, evaluating deficit disorders and planning interventions, as counseling and psychotherapy. Indeed, the results of this survey confirm the relationship between attachment styles and emotional dysregulation, and between attachment styles and metacognition in patients with personality disorders, suggesting that disorganized attachment may be one of risk factors for the development of personality disorders.

Further research aims to clarify the role of these features, enlarging the personality disorders sample to more accurately estimate the role of Adult attachment, from one hand, in emotional dysregulation and, from the other hand, in Metacognitive functioning.

\section{References}

Ainsworth, M. D. S. (1982). Attachment: Retrospect and Prospect. In C. M. Parkes, \& J. Stevenson-Hinde (Eds.), The Place of Attachment in Human Behavior (pp. 3-30). New York: Basic Books.

Ainsworth, M. D. S. (1989). Attachments beyond Infancy. American Psychologist, 44, 709-716. http://dx.doi.org/10.1037/0003-066X.44.4.709.

Alaimo, S. M. (2012). Disturbi di personalità e psicoterapia: Prime evidenze dell'utilizzo di una batteria di test per l'assessment del funzionamento metacognitivo e del deficit attentive. Congresso Nazionale Società Italiana Terapia Comportamentale e Cognitiva (SITCC), Roma, 5 October 2012, Video Registration.

Alaimo, S. M., \& Schimmenti, A. (2013). Metacognitive Functions Screening Scale—30 Items (MFSS-30). Giovanni Fioriti Editore, Roma, 32, 145-162.

Bagby, R. M., Parker, J. D. A., \& Taylor, G. J. (1994). The Twenty-Item Toronto Alexithymia Scale-I. Item Selection and Cross-Validation of the Factor Structure. Journal of Psychosomatic Research, 38, 23-32. http://dx.doi.org/10.1016/0022-3999(94)90005-1

Baron-Cohen, S., Leslie, A., \& Frith, U. (1985). Does the Autistic Child Have a Theory of Mind? Cognition, 21, 37-46. http://dx.doi.org/10.1016/0010-0277(85)90022-8

Bartholomew, K. (1990). Avoidance of Intimacy: An Attachment Perspective. Journal of Social and Personal Relationships, 7, 147-178. http://dx.doi.org/10.1177/0265407590072001

Basile, G., Quadrana, L., \& Monniello, G. (2009). Alexithymia and Personality Disorders in Adolescence. Psichiatria dell'infanzia e dell'adolescenza, 76, 513-531.

Bateman, A. W., \& Fonagy, P. (2004). Psychotherapy of Borderline Personality Disorder: Metallization Based Treatment. Oxford: Oxford University Press. 
Bowlby, J. (1979). The Making and Breaking of Affectional Bonds. London: Tavistok Publication.

Bowlby, J. (1980). Attachment and Loss. Vol. 3: Loss, Sadness and Depression. New York: Basic Books.

Brennan, K. A., Clark, C. L., \& Shaver, P. R. (1998). Self-Report Measurement of Adult Attachment: An Integrative Overview. In J. A. Simpson, \& W. S. Rholes (Eds.), Attachment Theory and Close Relationships (pp. 46-76). New York: Guilford.

Brüne, M., Abdel-Hamid, M., Lehmkämper, C., \& Sontag, C. (2007). Mental State Attribution, Neurocognitive Functioning, and Psychopathology: What Predicts Poor Social Competence in Schizophrenia Best? Schizophrenia Research, 92, 151159. http://dx.doi.org/10.1016/j.schres.2007.01.006

Carcione, A., \& Falcone, M. (1999). La metacognizione come costrutto fondamentale per la psicoterapia. In A. Semerari (a cura di), Psicoterapia cognitiva del paziente grave (pp. 9-42). Milano: Raffaello Cortina.

Carcione, A., Falcone, M., Magnolfi, G., \& Manaresi, F. (1997). La funzione metacognitiva in psicoterapia: Scala di Valutazione della Metacognizione (S.Va.M.). Psicoterapia, 9, 91-97.

Caretti, V., Porcelli, P., Solano, L., Schimmenti, A., Bagby, R. M., \& Taylor, G. J. (2011). Reliability and Validity of the Toronto Structured Interview for Alexithymia in a Mixed Clinical and Nonclinical Sample from Italy. Psychiatry Research, 187, 432-436. http://dx.doi.org/10.1016/j.psychres.2011.02.015

Collins, N. L., \& Read, S. J. (1990). Adult Attachment, Working Models, and Relationship Quality in Dating Couples. Journal of Personality and Social Psychology, 58, 644-663. http://dx.doi.org/10.1037/0022-3514.58.4.644

Dimaggio, G., \& Lysaker, P. H. (2011). Metacognizione e psicopatologia. Valutazione e trattamento. Milano: Raffaello Cortina Editore.

Flavell, J. H. (1976). Metacognitive Aspects of Problem Solving. In L. B. Resnick (Ed.), The Nature of Intelligence (pp. 231-236). Hillsdale, NJ: Lawrence Erlbaum.

Flavell, J. H. (1979). Metacognition and Cognitive Monitoring: A New Area of Cognitive-Developmental Inquiry. American Psychologist, 34, 906-911. http://dx.doi.org/10.1037/0003-066X.34.10.906

Flavell, J. H. (1981) Cognitive Monitoring. In W. P. Dickson (Ed.), Children's Oral Communication (pp. 35-60). New York: Academic Press.

Flavell, J. H. (1987). Speculation about the Nature and Development of Metacognition. In F. Weinert, \& R. Kluwe (a cura di), Metacognition, Motivation, and Understanding (pp. 21-29). Hillsdale, NJ: Lawrence Erlbaum.

Fonagy, P. (1991). Thinking about Thinking: Some Clinical and Theoretical Considerations in the Treatment of Borderline Patient. International Journal of Psychoanalysis, 72, 639-656.

Fonagy, P. (2001). Attachment Theory and Psychoanalysis. New York: Other Press.

Fonagy, P., \& Target, M. (2006). The Mentalization-Focused Approach to Self Pathology. Journal of Personality Disorders, 20, 544-576. http://dx.doi.org/10.1521/pedi.2006.20.6.544

Fraley, R. C., Waller, N. G., \& Brennan, K. A. (2000). An Item Response Theory Analysis of Self-Report Measures of Adult Attachment. Journal of Personality and Social Psychology, 78, 350-365. http://dx.doi.org/10.1037/0022-3514.78.2.350

Hazan, C., \& Shaver, P. R. (1987). Romantic Love Conceptualized as an Attachment Process. Journal of Personality and Social Psychology, 52, 511-524. http://dx.doi.org/10.1037/0022-3514.52.3.511

Kobak, R., \& Hazan, C. (1991). Attachment in Marriage: The Effect of Security and Accuracy of Working Models. Journal of Personality and Social Psychology, 60, 861-869. http://dx.doi.org/10.1037/0022-3514.60.6.861

Main, M. (1991). Metacognitive Knowledge, Metacognitive Monitoring, and Singular (Coherent) vs. Multiple (Incoherent) Models of Attachment: Findings and Directions for Future Research. In P. Harris, J. Stevenson-Hinde, \& C. Parkes (Eds.), Attachment across the Life Cycle (pp. 127-159). New York: Routledge.

Moriguchi, Y., Touroutoglou, A., Dickerson, B. C., \& Barrett, L. F. (2013). Sex Differences in the Neural Correlates of Affective Experience. Social Cognitive and Affective Neuroscience, 9, 591-600. http://dx.doi.org/10.1093/scan/nst030

Picardi, A., Vermigli, P., Toni, A., D’amico, R., Bitetti, D., \& Pasquini, P. (2002). Il questionario "Experiences in Close Relationship” (ECR) per la valutazione dell'attaccamento negli adulti: Ampliamento delle evidenze di validità per la versione italiana. Giornale Italiano di Psicopatologia, 8, 282-294.

Premack, D., \& Woodruff, G. (1978). Does the Chimpanzee Have a Theory of Mind? Behavioral and Brain Sciences, 4, 515-526. http://dx.doi.org/10.1017/S0140525X00076512

Semerari, A., Carcione, A., Dimaggio, G., Falcone, M., Nicolò, G., Procacci, M., \& Alleva, G. (2003). How to Evaluate Metacognitive Functioning in Psychotherapy? The Metacognition Assessment Scale and Its Applications. Clinical Psychology and Psychotherapy, 10, 238-261. http://dx.doi.org/10.1002/cpp.362

Semerari, A., D’angerio, S., Popolo, R., Cucchi, M., Ronchi, P., Maffei, C., Dimaggio, G., Nicoló, G., \& Carcione, A. (2008). 
L’Intervista per la Valutazione della Metacognizione (IVaM). Descrizione dello strumento. Cognitivismo Clinico, 5, 174-192.

Taylor, G. J., Bagby, R. M., \& Parker, J. D. A. (1997). Disorders of Affect Regulation: Alexithymia in Medical and Psychiatric Illness. Cambridge: Cambridge University Press. http://dx.doi.org/10.1017/CBO9780511526831 